\title{
Assessment of the Prevalence of Depression and Associated Factors in Ambo Prison, Ambo Town, West Shewa Zone, Oromia Region, Ethiopia
}

\author{
Hunduma Dinsa Ayeno Bitania Daniel
}

\begin{abstract}
Background: It is presumed that depression is the major psychological problem among inmates as they are believed to be under an vast mental and physical stress compared to the general population.Objective: The aim of this study is to assess the prevalence of depression and associated factors in Ambo Prison, Ambo Town, West Shewa Zone, Oromia Region, Ethiopia.Method: An institutional based cross-sectional study was conducted to assess the prevalence of depression. The samples were selected by systematic random sampling technique and data was collected by using structured questionnaire in accordance with PHQ-9 screening and scoring Scale. The sample was calculated by using sample size calculating formula and correction formula. The data was coded and entered into computer and analyzed by using SPSS version 20. Bivariate and multivariate logistic regressions were done for association, and finally frequencies and other descriptive statistics were computed.Result: The overall prevalence of depression among inmates was 54.4\%, of which 53 (15.4\%), 31 (9\%), 29 (8.4\%), and $74(21.5 \%)$ met the criteria for mild, moderate, moderately severe, and severe depression respectively. Factors associated with depression were future apprehension and the environments of the prison. However, multiple logistic regression analysis revealed that the strongest predictor of depression was suicidal ideation [AOR $=25.547 ; 95 \% \mathrm{CI}: 12.166$, 53.648, $\mathrm{p}<0.01]$. Conclusion: In conclusion, the prevalence of depression among inmates in Ambo Prison were found to be high, in which most of them met the criteria for severe depression contributing to suicidal ideation and actual attempts.
\end{abstract}

Keywords: Associated factors, Ambo, Depression, Prevalence, Severity

DOI: $10.7176 / \mathrm{JHMN} / 94-01$

Publication date:October $31^{\text {st }} 2021$

\section{INTRODUCTION}

Prison is an institution, usually under state control, where sentenced prisoners and accused persons incarcerated in custody are legally held as a punishment or while awaiting trial. The prison system is under a considerable pressure making it more difficult to manage prisoners' mental well-being by annulling the formation and development of basic human values, which in turn may contribute to stigmatization and disruption of conducts that may lead to temporary or even irreversible psychological sequel $(1,2,3)$.

Evidences suggest that captivity settings lead to anxiety, depression, self-harming or hetero-aggressive behavior, obsessions, psychoactive substance abuse, and suicide by reducing a person's bio-psychosocial balance to such a degree that the memory of a individual negative event dominates all other experiences and disturb the ability to cope with reality $(2,4,5)$. Furthermore, anticipated suffering in life outside of incarceration, fear of family abandonment, guilt for being absent from raising and educating their children, losing their right to the social importance of work, identity loss, social discrimination that impairs prospects for working outside of the criminal context, and social recognition also contribute to psychiatric problems among this population (6).

From the realistic mental health problems that can be acquired while incarcerated, depression has an overriding prevalence. It refers to a wide range of mental health problems characterized by a loss of interest and entertainment in normal activities, exhausted mood, and a range of associated emotional, cognitive, physical, and behavioral symptoms (7).

According to the Diagnostic and Statistical Manual of Mental Disorders, 5th edition, five or more of the following symptoms have been present during the same 2 weeks period and represent a change from previous functioning: at least one of the symptoms is either (1) depressed mood (e.g., feels sad, empty, hopeless) most of the day, nearly every day or (2) loss of interest or pleasure in all, or almost all, activities most of the day, nearly every day. The remaining 7 symptoms include (3) significant weight loss when dieting or weight gain (e.g., a change of more than $5 \%$ of body weight in a month), or decrease or increase in appetite nearly every day, (4) insomnia or hypersomnia nearly every day, (5) psychomotor agitation or retardation (feelings of restlessness or being slowed down) nearly every day, (6) fatigue or loss of energy nearly every day, (7) feelings of worthlessness or excessive or inappropriate guilt (which may be delusional) nearly every day, (8) diminished ability to think or concentrate, or indecisiveness, nearly every day, and (9) recurrent thoughts of death (not just fear of dying), recurrent suicidal ideation without a specific plan or a suicide attempt or a specific plan for committing suicide are the symptoms that indicate the presence of depression in an individual (8).

Globally, depression is a common disorder with more than 300 million persons affected. It is different from 
conventional fluctuation and short-lived emotional disorder in response to difficult challenges and dilemmas of everyday life. Obviously, when long-lasting and with moderate/severe intensity, it may become a dangerous health condition. It has a substantial potential morbidity and mortality, contributing to an incidence and adverse results of medical illness, disruption in interpersonal relationships, substance abuse, and lost work time. At its worst, depression can lead to suicide; close to 800,000 people die of suicide every year. Suicide is the second leading cause of death in 15-29 years olds $(9,10)$.

In developing countries, the prevalence rates of depression are higher (11).Gender differences exist with respect to effects of imprisonment on both male and female inmates. Mental health problems have been observed to be higher among incarcerated inmates compared to the general population and are a significant source of morbidity among prisoners (12, 13, and 14).

Depression is a significant contributor to the global burden of disease and affects people in all communities across the world. Lifetime prevalence estimates vary widely from $3 \%$ in Japan to $17 \%$ in the US. However, epidemiology data have shown higher rates in the Middle East, North Africa, and Russia than other countries (15). By 2020, depression is set to become the second largest cause of disease burden and the third most common reason for primary care consultation (16).

In Ethiopia, depression contributes to about $6.5 \%$ of burden of disease; the highest share of burden compared to other form of mental disorders $(17,18)$. WHO has identified strong links between depression and other Noncommunicable Disorders and Diseases like substance abuse, HIV/AIDS, Diabetes, Asthma, and heart diseases; the opposite is also true; meaning that people with these other condition have a higher risk of depression. Depression is also an important risk factor for suicide which claims hundreds of thousands of lives each year (9).

Among the world's population, prisoners are more prone to depression than other groups. Once prisoners are incarcerated, they will not have the freedom to execute their own decisions; communication and relationships with families and friends are circumscribed. While it is understandable that any imprisoned individual would be foreseeably depressed, it is important to comprehend depression from the perspective of a mental illness (19).

Recognition and treatment of depression often take place in primary, secondary, and tertiary healthcare with trained and qualified personnel (20). However, this level of personnel are lacking among prisons. Hence, the conspicuous difficulty in the assessment and treatment of individuals in such category. Furthermore, this condition is worsened by the fact that the proportions of the prisoners with possible clinically diagnosable psychiatric morbidity and significant depressive symptoms are quite high. This could be because the health systems in developing countries is poorly organized and poorly funded as compared with the health care system in industrialized countries $(21,22,23)$.

Ethiopia, as in most countries, prison systems shoulder the burden of providing healthcare service. They are, however, ill-equipped to perform this responsibility due to limited resources (human and capital), corruption, and the ever-increasing number of inmates. In many countries (including Ethiopia), prison establishments are struggling to provide minimal mental health services to prisoners and only a few have acquainted with psychiatrists. The provisions for the mentally disordered prisoners have also been observed to be inadequate. Given the limited resources of most prisons, it seems doubtful whether most prisoners with these illnesses receive appropriate care. In Ethiopia, mental health has been one of the most disadvantaged health programs both in terms of facilities and trained manpower. But during the last decades, encouraging efforts have been taken to expand services throughout the country $(24,25)$.

The experience of incarceration appears to influence the physical and mental health of inmates as self-reported health problems increase with inmate duration of incarceration (26). The impact of marital status, parental status, and social support (both inside and outside of the jail) on various dimensions of mental health has also been examined in studies. Available data indicate that imprisonment is severely stressful for many inmates. This may be because prisons were not set up to be corrective. Rather, they were punitive in the criminal justice system. Prison environments, which are often characterized by gross infrastructural decay and poor amenities, are potentially damaging situations. Thus, their negative psychological effects must be taken seriously, carefully evaluated, purposefully regulated, and controlled. To this end, incarcerations should be viewed, not only as a correctional opportunity, but also as an opportunity to engage clinical and social resources for the full benefit of these inmates $(27,28,29)$.

Education and the implementation of specific stress-management programs to the inmates and officials may be beneficial to ensure that stress within prisons is confined to tolerable limits. This study will be undertaken to provide information on the prevalence, burden, and associated factors of depression in the population of the prisoners in Ambo Prison, Ambo Town, West Shewa Zone, Oromia Region, Ethiopia. The study is also believed to provide data that may assist in the formulation of the necessary preventive and treatment strategies on the target population. To the best knowledge of the researcher and to the extent of available literature reviews, this study will be the first to be conducted on the prevalence of depression and associated factors among prisoners in Ambo Prison, Ambo Town, West Shewa Zone, Oromia Region, Ethiopia.Therefore the aimof this study was to assess the prevalence of depression disorder and associated factors among inmates in Ambo Prison, Ambo Town, West 
Shewa Zone, Oromia Region, Ethiopia, 2018 G.C.

\section{METHODS AND MATERIALS}

\section{Study Period and Area}

The study was conducted from April - May 30, 2018 in Ambo Prison which is situated 114 k.m. west of the capital city of Ethiopia, Addis Ababa, in the town of Ambo. The prison located in Kebele 06 is one of the several prisons in the area which holds unlawful individuals.

The town has one Referral Hospital, One General Hospital, one MCH special Clinic, and two Health Centers in addition to many other private facilities.

\section{Study Design}

An institutional based cross-sectional study was conducted among inmates in Ambo Prison, Ambo Town, West Shewa Zone, Oromia Region, Ethiopia, 2018 G.C.

\section{Population}

\section{Source Population}

The source population was all inmates of Ambo Prison, Ambo Town, West Shewa Zone, Oromia Region, Ethiopia, 2018 G.C.

\section{Study Population}

The study population was every $5^{\text {th }}$ inmates in Ambo Prison on the register in both the male and female sections of the prisons.

\section{Inclusion Criteria}

Inmate who were acquiescent to give verbal informed consent regardless of their age and sex.

\section{Exclusion Criteria}

$>$ Inmates who declined to give consent to participate in the study.

Inmates who were too ill to participate in the study.

$>$ New inmates $(<2$ weeks $)$.

\section{Sample Size and Sampling Technique}

The study sample was determined according to the fine population correction (fpc) principle, where sample size for a study with a source population greater than 10,000 is calculated with the formula:

$\mathbf{n}=\frac{Z^{2} p q}{d^{2}}$

Where,

$\mathrm{n}=$ is the sample size,

$\mathrm{Z}^{2}=$ is the abscissa of the normal curve that cut off an area at the tail (1- equals the desired confidence level, e.g., $95 \%$ ), usually set at 1.96 .

$\mathrm{d}=$ is the desired level of precision,

$\mathrm{p}=$ is the estimated proportion of an attribute that is present in the population $(0.5)$, and

$\mathrm{q}=1-\mathrm{p}(0.05)$, which corresponds to the degree of accuracy desired.

$\mathrm{n}=\frac{Z^{2} p q}{d^{2}}=\frac{(1.96)^{2}(0.5)(0.05)}{(0.05)^{2}}=384$

If the study population was greater than 10,000 , the required sample size would have been 384 . However, in this study, the population was 1,800 (less than 10,000), the required sample size was therefore calculated using the Finite Population Correction for Proportions formula.

$\mathbf{n}=\frac{n_{\circ}}{1+\frac{\left(n_{o}-1\right)}{N}}$

Where,

$\mathrm{n}=$ the desired sample size when population is $<10,000$,

$\mathrm{n}_{\mathrm{o}}=$ the desired sample size when population is $>10,000$, and

$\mathrm{N}=$ is the estimated study population.

$\mathbf{n}=\frac{\mathbf{3 8 4}}{\mathbf{1 + ( 3 8 4 - 1 )}}$

This gave a sample size of 317 .

Using an assumed non-response rate of $15 \%$, a corrected sample size was calculated with the formula:

$\frac{\text { sample size }}{100-15} \times 100=\frac{317}{0.85}=372.9$

Approximately, 373 was obtained to make room for non-responders. 
A systematic random sampling was done by using the prisons register (sampling frame) and the sampling interval size was calculated by using the formula:

$N / n=k$

Where,

$\mathrm{N}=$ is the total population (1800),

$\mathrm{n}=$ is the sample size (373), and

$\mathrm{k}=$ is the sampling interval size.

$\frac{1800}{373}=4.8$ (approximately 5)

Therefore, every $5^{\text {th inmate }}$ on the register in both the male and female sections of the prison was selected.

\section{Data Collection}

Relevant information was collected by using structured questionnaire prepared to be filled by prison inmates. The questionnaire that was designed comprised of questions pertaining to socio-demographic data, clinical information, and penal characteristics.

\section{Study Variables \\ Dependent Variables}

$>$ Prevalence of depression

\section{Independent Variables}

$>$ Socio-demographic characteristics of prison inmates

$>$ Penal characteristics of prison inmates

$>$ Health related characteristics of prison inmates

$>$ Discontinuation of substance use due to incarceration

\section{Data Quality Assurance}

To ensure the quality of data, the questionnaire was pretested by taking $5 \%$ of the total sample size, and imperative corrections were done after the pretest prior to the actual data collection. The data was also authenticated for completeness and any missing information at each point. Furthermore, data was validated during entry and compilation before analysis.

\section{Data Analysis}

Data was entered into a micro-computer and analyzed using Statistical Package for Social Sciences (SPSS) software for windows version 20. Data handling was confidential.

\section{Ethical Consideration}

Ethical clearance was requested and obtained from the research ethical review committee of College of Medicine and Health Science, University of Ambo. Subsequently, an official letter was prepared to get authorization to collect data at respective faculties. Verbal consent was sought from concerned staffs and confidentiality of the information was assured in such a way that no disclosure of any name of the participants in relation to finding will be made.

\section{Operational Definitions}

Depression: A mental condition characterized by feelings of severe despondency and dejection, typically also with feelings of inadequacy and guilt, often accompanied by lack of energy and disturbance of appetite and sleep. Incarceration: The state of being confined in prison.

Offense afflicted: The type of offense that the inmate afflicted (the type of crime the inmate was convicted with). It was classified into violent crime (murder, female trafficking, and kidnapping), sexual offense (forced sexual intercourse (rape), and attempted rape), drug crime (use, possession, manufacture, or distribution of drugs classified as having a potential for abuse), property crime (burglary, robbery, motor vehicle theft, and theft), and other crimes (fraud, wildlife and forest crime, and other non-violent crimes).

Prison: A building in which people are legally held as a punishment for a crime they have committed or while awaiting trial.

Sentence served: Type of punishment assigned to a defendant found guilty by a court, or fixed by law for a particular offense. It was classified into EPP (Extended Sentence for Public Protection), IPP (Indeterminate Sentence for Public Protection), Simple Imprisonment Sentence, Life sentence, and Suspected in Remand.

Suspect in Remand: A defendant in custody while awaiting trial. 


\section{RESULT}

From the 373 subjects involved in the study, 344 (92.2\%) had given complete information by filling in the provided questionnaires appropriately, while $29(7.8 \%)$ had failed to do so. Thus, declared ineligible.

\section{Socio-demographic characteristics of study participants (prison inmates) in Ambo Prison}

The $344(92.2 \%)$ study participants (prison inmates) ranged in age from 16 to 78 years, with a mean age of 24.1 (50 \pm 11.32$)$, most of whom were between the age of 18 and 25 years (53\%). 15 inmates, representing $4.4 \%$ of the study population, were found to be underage, having ages below the legal age of 18 years and 28 inmates, representing $8.1 \%$ of the study population, their ages were found to be unknown. From the $344(92.2 \%)$ study participants, 341 were males representing $99.1 \%$ of the sample population, while 3 were females $(0.9 \%)($ see Table 2 .

Out of 344(92.2\%) inmates 216 followed Christinity accounting for 62.8\%, while $12(3.5 \%), 106(30.8 \%), 4$ $(1.2 \%)$, and $6(1.7 \%)$ followed, Islamism, Wa'aqefeta, Atheism, and other unpecified religions respectively; 340 $(98.8 \%)$ were among the Oromo ethnic group, $2(0.6 \%)$ were among the Amhara ethnic group, while $2(0.6 \%)$ were mixed; $16(4.7 \%)$ were illiterates (unable to read or write), $15(4.4 \%)$ had only reached pre-primary education level, $119(34.6 \%)$ had only reached primary education level, $142(41.3 \%)$ had only reached secondary education level, while 52 (15\%) had reached higher education levels (Universities or colleges); 203 (59\%) were singles, 129 $(37.5 \%)$ were married, $9(2.6 \%)$ were divorced, and $3(0.9 \%)$ were widowed; $135(39.2 \%)$ had children, $1(0.3 \%)$ had a deceased child, while 208 (60.5\%) didn't have children; $72(20.9 \%)$ were farmers for own consumptions prior to incarceration, $12(3.5 \%)$ were farmers for commercial products, $36(10.5 \%)$ were governmnet employees, $26(7.6 \%)$ were private employees, $15(4.4 \%)$ were engaged in family businesses, while $177(51.5 \%)$ were unemployed.

Table 1 Socio-demographic characteristics of study participants (prison inmates) in Ambo Prison, Ethiopia. [Descriptive statistics: $n=$ frequency, $\%=$ percentage]

\begin{tabular}{|c|c|}
\hline Variable & $\mathbf{N}(\%)$ \\
\hline \multicolumn{2}{|l|}{ Sex } \\
\hline Male & $341(99.1)$ \\
\hline Female & $3(0.9)$ \\
\hline \multicolumn{2}{|l|}{ Age } \\
\hline$<18$ years & $15(4.4)$ \\
\hline $18-25$ years & $182(53)$ \\
\hline $26-33$ years & $70(20.3)$ \\
\hline $34-41$ years & $28(8.1)$ \\
\hline 42-49 years & $11(3.2)$ \\
\hline 50-57 years & $6(1.7)$ \\
\hline $58-65$ years & $3(0.9)$ \\
\hline$>65$ years & $1(0.3)$ \\
\hline Unknown & $28(8.1)$ \\
\hline \multicolumn{2}{|l|}{ Religion } \\
\hline Orthodox & $106(30.8)$ \\
\hline Muslim & $12(3.5)$ \\
\hline Catholic & $6(1.7)$ \\
\hline Protestant & $104(30.2)$ \\
\hline Wa'aqefeta & $106(30.8)$ \\
\hline Atheist & $4(1.2)$ \\
\hline Others & $6(1.7)$ \\
\hline \multicolumn{2}{|l|}{ Ethnic Group } \\
\hline Oromo & $340(98.8)$ \\
\hline Amhara & $2(0.6)$ \\
\hline Mixed & $2(0.6)$ \\
\hline \multicolumn{2}{|l|}{ Education Status } \\
\hline Illiterate & $16(4.7)$ \\
\hline Pre-primary education & $15(4.4)$ \\
\hline Primary education & $119(34.6)$ \\
\hline Secondary education & $142(41.3)$ \\
\hline Higher education levels & $52(15.1)$ \\
\hline
\end{tabular}




\begin{tabular}{|c|c|}
\hline Variable & N (\%) \\
\hline \multicolumn{2}{|l|}{ Marital Status } \\
\hline Single & $203(59)$ \\
\hline Married & $129(37.5)$ \\
\hline Divorced & $9(2.6)$ \\
\hline Widowed & $3(0.9)$ \\
\hline \multicolumn{2}{|l|}{ Parenthood } \\
\hline Have children & $135(39.2)$ \\
\hline Don't have children & $208(60.5)$ \\
\hline Deceased children & $1(0.3)$ \\
\hline \multicolumn{2}{|l|}{ Occupation Prior to Incarceration } \\
\hline Unemployed & $177(51.5)$ \\
\hline Farmer for own consumption & $72(20.9)$ \\
\hline Farmer for commercial products & $12(3.5)$ \\
\hline Government employee & $36(10.5)$ \\
\hline Private employee & $26(7.6)$ \\
\hline Self-employed & $15(4.4)$ \\
\hline Family business & $6 \quad(1.7)$ \\
\hline
\end{tabular}

\section{Penal characteristics of study participants (prison inmates) in Ambo Prison}

Out of 344 (92.2\%) inmates, 154 were serving an Extended Sentence for Public Protection (EPP) representing $44.8 \%$ of the study population, 151 were serving an Indeterminate Sentence for Public Protection (IPP) representing 43.9\%, 16 were serving a Simple Imprisonment Sentence representing $4.7 \%$, 14 were serving Life Sentence representing 4.1\%, and 9 were Suspects in Remand representing $2.6 \%$ of the study population in which $324(94.2 \%)$ were first-time offenders, while $20(5.8 \%)$ were previously incarcerated; $7(2 \%)$ of the study participants had stayed from 2 weeks - 1 months, while $54(15.7 \%), 45(13.1 \%), 80(23.3 \%)$, and $158(45.9 \%)$ had stayed from 1 - 6 months, $7-12$ months, $1-2$ years, and $>2$ years respectively; 23 of the inmates were convicted of property crime accounting for 9.4\%, $206(59.8 \%)$ of violent crime, 19 (5.5\%) of sexual offense, $1(0.3 \%)$ of drug crime, and 86 (25\%) of other crimes; 209 (54.4\%) committed the offense unintentionally, $56(16.3 \%)$ had reasons that remained unspecified, $6(1.7 \%)$ committed the offense prevailed upon existing mental illness that remained unspecified in which $1(16.7 \%)$ acknowledged the presence of mental illness because of the society's insistence, $4(66.6 \%)$ were diagnosed at a health center, and $1(16.7 \%)$ was diagnosed traditionally $(2(33.3 \%)$ were taking medications that remained unspecified, $3(50 \%)$ had discontinued their medications after being incarcerated, and 1 (16.7\%) was not taking any medication for that matter), while $73(21.2 \%)$ supposed unjust incarceration, thus, no justification needed; 131 (38.1\%) received visits while in prison, and 213 (61.9\%) didn't; $82(23.8 \%)$ had a work performance while in prison, while $262(76.2 \%)$ didn't have.

Table 2: Penal characteristics of study participants (prison inmates) in Ambo Prison, Ethiopia. [Descriptive statistics: $n=$ frequency, $\%=$ percentage.]

\begin{tabular}{|l|l|}
\hline Variable & N $(\%)$ \\
\hline Incarceration Period & $7(2.0)$ \\
\hline 2 weeks - 1 months & $54(15.7)$ \\
\hline $1-6$ months & $45(13.1)$ \\
\hline $7-12$ months & $80(23.3)$ \\
\hline $1-2$ years & $158(45.9)$ \\
\hline$>2$ years & $324(94.2)$ \\
\hline Previous Incarceration & $20(5.8)$ \\
\hline No & $154(44.8)$ \\
\hline Yes & $151(43.9)$ \\
\hline Sentence Served & $16(4.7)$ \\
\hline EPP & $14(4.1)$ \\
\hline IPP & $9(2.6)$ \\
\hline Simple Imprisonment Sentence &
\end{tabular}




\begin{tabular}{|c|c|}
\hline Variable & $\mathbf{N}(\%)$ \\
\hline \multicolumn{2}{|l|}{ Offense Afflicted } \\
\hline \multicolumn{2}{|l|}{ Property crimes } \\
\hline Theft & $23(6.7)$ \\
\hline Robbery & $3(0.9)$ \\
\hline Motor Vehicle Theft & $1(0.3)$ \\
\hline Burglary & $5(1.5)$ \\
\hline \multicolumn{2}{|l|}{ Violent crimes } \\
\hline Murder & $127(36.9)$ \\
\hline Attempted Murder & $17(4.9)$ \\
\hline Female Trafficking & $19(5.5)$ \\
\hline Physical Abuse & $43(12.5)$ \\
\hline \multicolumn{2}{|l|}{ Sexual offenses } \\
\hline Forced Sexual Intercourse (Rape) & $9(2.6)$ \\
\hline Attempted Forced Sexual Intercourse & $10(2.9)$ \\
\hline \multicolumn{2}{|l|}{ Drug crimes } \\
\hline Drug Crimes & $1(0.3)$ \\
\hline \multicolumn{2}{|l|}{ Other crimes } \\
\hline Corruption & $3(0.9)$ \\
\hline Wildlife and Forest Crimes & $1(0.3)$ \\
\hline Politics Related Issues & $7(2.0)$ \\
\hline Supposed Unjust Imprisonment & $73(21.2)$ \\
\hline Others/unspecified & $2(0.6)$ \\
\hline \multicolumn{2}{|l|}{ Reasons For Afflicting Offence } \\
\hline It was not intentional & $209(60.8)$ \\
\hline It was not unintentional & $56(16.3)$ \\
\hline Prevailed upon existing mental illness & $6(1.7)$ \\
\hline $\begin{array}{l}\text { Supposed unjust imprisonment. Hence, no justification } \\
\text { required. }\end{array}$ & $73(21.2)$ \\
\hline \multicolumn{2}{|l|}{ Visits While in Prison } \\
\hline Receive visits & $131(38.1)$ \\
\hline Do not receive visits & $213(61.9)$ \\
\hline \multicolumn{2}{|l|}{ Work performance while in prison } \\
\hline Present & $82(23.8)$ \\
\hline Absent & $262(76.2)$ \\
\hline
\end{tabular}

Health-related characteristics of study participants (prison inmates)

Out of $344(92.2 \%)$ inmates, 13 had an unchanged overall health status compared to times before incarceration representing $32.8 \%$ of the sample population, 83 had an improved overall health status compared to times before incarceration representing $24.1 \%$ of the sample population, and 148 had a worsened overall health status compared to times before incarceration representing $43 \%$ of the sample population.

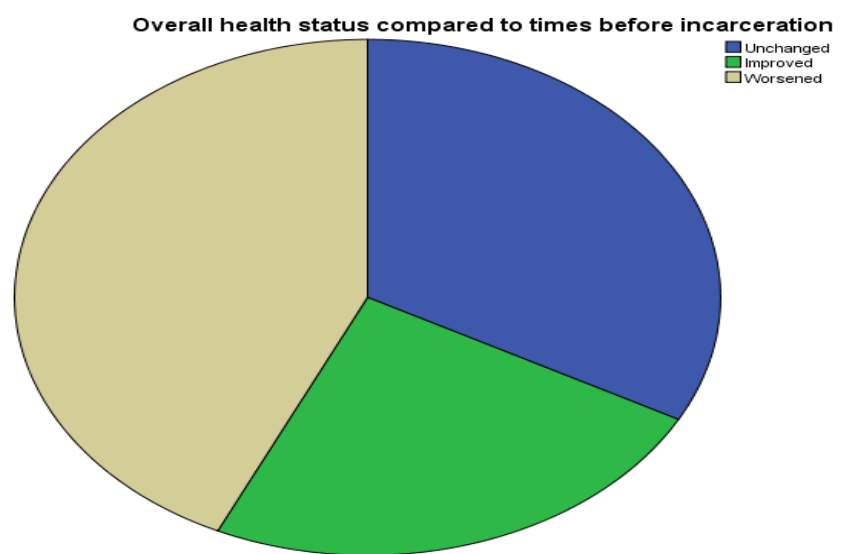

Figure 1 Overall health status compared to times before incarceration of study participants (prison inmates) in Ambo Prison, Ambo Ethiopia 
Out of $344(92.2 \%)$ inmates, 71 had a very good self-rated overall health status representing $20.6 \%$ of the sample population, 154 had a good self-rated overall health status representing $44.8 \%$ of the sample population, 90 had a bad self-rated overall status representing $26.2 \%$ of the sample population, and 29 had a very bad selfrated overall health status of the sample population; $201(58.4 \%)$ were healthy at the time of the study period, and $143(41.6 \%)$ were ill among which 50 were treated for their illness that remained unspecified and unrated as chronic or acute illness representing 35\%, while $93(65 \%)$ were not.

Table 3 Health characteristics of study participants (prison inmates) in Ambo Prison, Ethiopia. [Descriptive statistics: $\mathbf{n}=$ frequency, $\%=$ percentage.

\begin{tabular}{|l|l|}
\hline Variable & N $(\mathbf{\%})$ \\
\hline Self-rated overall health status & $71(20.6)$ \\
\hline Very good & $154(44.8)$ \\
\hline Good & $90(26.2)$ \\
\hline Bad & $29(8.4)$ \\
\hline Very bad & $113(32.8)$ \\
\hline Overall health status compared to times before incarceration \\
\hline Unchanged & $83(24.1)$ \\
\hline Improved & $148(43)$ \\
\hline Worsened & $201(58.4)$ \\
\hline Current health status & $143(41.6)$ \\
\hline Healthy & $50(15)$ \\
\hline Ill & $93(27)$ \\
\hline Hospital visits & $2018)$ \\
\hline Sought treatment & \\
\hline Didn't seek treatment & \\
\hline Not ill & \multicolumn{1}{|l|}{} \\
\hline
\end{tabular}

Discontinuation of substance use of study participants (prison inmates) due to incarceration

Out of $344(92.2 \%)$ of inmates, 61 (17.7\%), $10(2.9 \%), 18(5.2 \%), 7(2 \%), 19(5.5 \%), 2(0.6 \%), 2(0.6 \%)$, and 4 (1.2\%) discontinued alcohol consumption, cigarette smoking, khat chewing, alcohol, cigarette, and khat use altogether, alcohol, khat, and illicit drugs use altogether, and all said substances altogether respectively, while 221 $(64.2 \%)$ didn't discontinue any substance use.

Table 4: Discontinued substance use due to incarceration of study participants (prison inmates) in Ambo Prison, Ethiopia. [Descriptive statistics: $n=$ frequency, $\%=$ percentage.]

\begin{tabular}{|l|l|}
\hline Variable & $\mathbf{N}(\%)$ \\
\hline Discontinued substances due to incarceration \\
\hline Alcohol & $61(17.7)$ \\
\hline Tobacco/cigarette & $10(2.9)$ \\
\hline Khat & $18(5.2)$ \\
\hline Illicit drugs & $7(2)$ \\
\hline Alcohol, cigarettes, and khat & $19(5.5)$ \\
\hline Alcohol, khat, and illicit drugs & $2(0.6)$ \\
\hline Cigarettes and khat & $2(0.6)$ \\
\hline All & $4(1.2)$ \\
\hline None & $221(64.2)$ \\
\hline
\end{tabular}

\section{Factors associated with depression}

From 344 (92.2\%) inmates, $229(66.6 \%)$ were influenced by factors associated with disconcerting sentiments that developed after incarceration while $115(33.4 \%)$ were not; $222(64.5 \%)$ were influenced by factors associated with circumscribed affairs while $122(35.5 \%)$ were not; $273(79.4 \%)$ were influenced by factors associated with future apprehension while, $71(20.6 \%) ; 201(58.4 \%)$ were influenced by factors associated with the environment of the prison while $143(41.6 \%)$ were not.

Prevalence and severity of depression and suicidal ideation among study participants (prison inmates)

Out of 344 (92.2\%) inmates, 187 (54.4\%) had depression, of which 53 (15.4\%) met the criteria for mild depression, $31(9 \%)$ for moderate depression, $29(8.4 \%)$ for moderately severe depression, and $74(21.5 \%)$ for severe depression, and 157 (45.6\%) didn't have depression. 


\section{Prevalence and severity of depression}

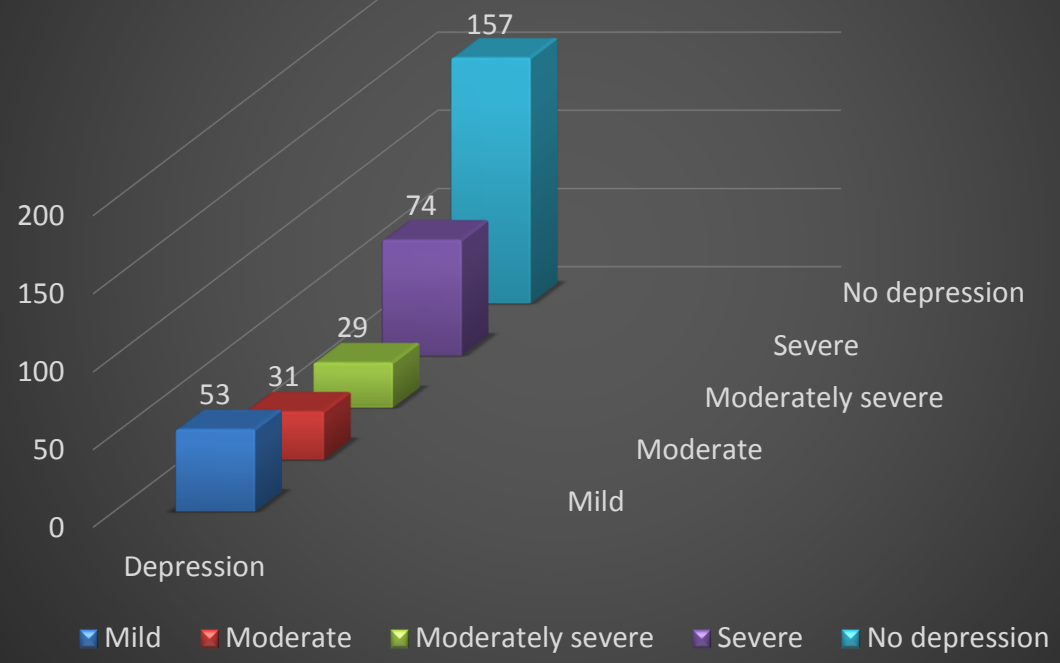

Figure 2: prevalence and severity of depression among study participants (prison inmates) in Ambo Prison, Ethiopia

Out of $344(92.2 \%)$ inmates 273 had acquaintance on depression representing $79.4 \%$ of the study population, while 71 (20.6) didn't; 121 (35.2\%) had suicidal ideation, $54(15.7 \%)$ had attempted an actual suicide among which $22((40.7 \%)$ had attempted suicide only once, while $14(25.9 \%), 9(16.7 \%), 3(5.6 \%)$, and $6(11.1 \%)$ had attempted suicide twice, 3-5 times, 5-10 times, and $>10$ times respectively, while $169(49.1 \%)$ had no thoughts of suicide. From these 54 (15.7\%) prison inmates who had attempted suicide, 11 accounting for $20.4 \%$ ventured drug overdosing as a method of suicide, $2(3.7 \%)$ ventured hanging, while the rest $41(75.9 \%)$ were unresponsive.

\section{Suicidal ideation}

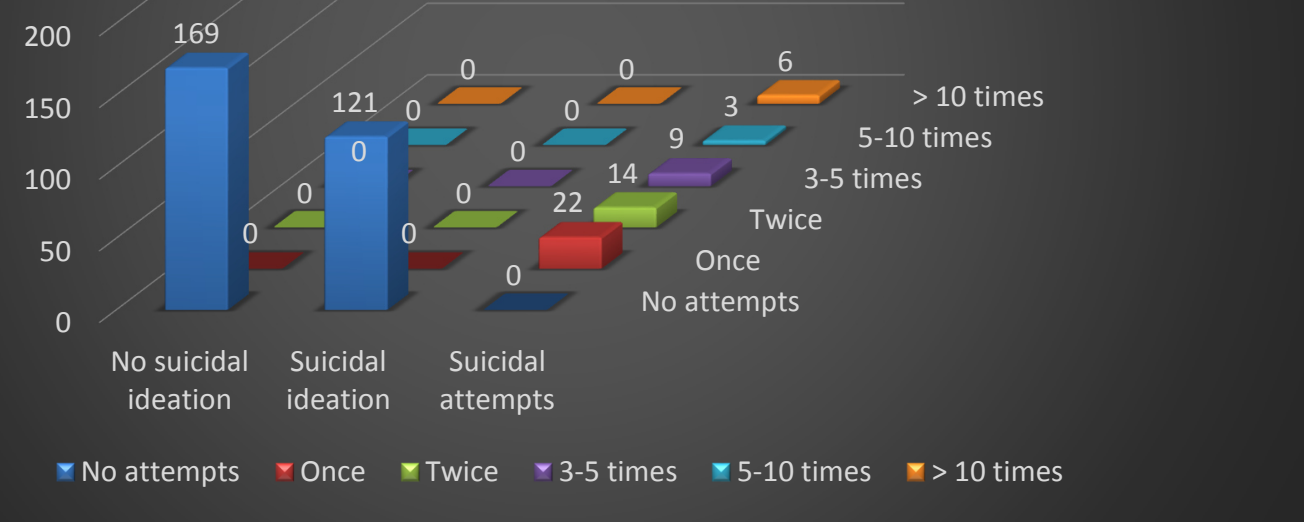

Figure 3: Suicidal ideation, suicidal attempts and frequency of attempts among study participants (prison inmates) in Ambo Prison, Ethiopia 


\section{Distribution of association}

Table 5 Distribution of association between socio-demographic characteristics, penal characteristics, health related characteristics, and associated factors by binary and multinomial logistic regression.

\begin{tabular}{|l|l|l|l|l|l|l|}
\hline \multirow{2}{*}{ Variables } & Depression & COR (95\% CI) & P-value & AOR (95\% CI) & P-value \\
\cline { 2 - 7 } & Yes & No & \multicolumn{1}{l|}{} \\
\hline Suicidal ideation \\
\hline Present & 150 & 37 & $0.47(0.027,0.082)$ & $<0.01$ & $25.547(12.166,53.648)$ & $<0.01$ \\
\hline Absent & 25 & 132 & 1 & & & 0.019 \\
\hline Factors associated with future apprehension & $0.402(0.234,0.690)$ & 0.001 & $2.818(1.184,6.704)$ & \\
\hline Yes & 161 & 26 & & & \\
\hline No & 112 & 45 & & & 0.017 \\
\hline Factors associated with the environment of the prison \\
\hline Yes & 110 & 77 & $5.368(3.315,8.69)$ & $<0.01$ & $0.043(0.003,0.564)$ & \\
\hline No & 33 & 124 & & & & \\
\hline
\end{tabular}

\section{Discussion}

This study disclosed the overall prevalence of depression among prisoners to be $54.4 \%$, in which $53(15.4 \%)$ met the criteria for mild depression, 31 (9\%) for moderate depression, 29 (8.4\%) for moderately severe depression, and $74(21.5 \%)$ for severe depression, and 157 (45.6\%) didn't have depression. The prevalence estimates were higher than the results of studies done in Port Harcourt prison, Northwest Amhara Regional State, Jimma Town Prison, and Nepal, where the prevalence rate of depression was $37 \%, 43.8 \%, 41.9 \%$, and $35.3 \%$ respectively. The study that was done in Port Harcourt Prison showed that $14.2 \%$ met the criteria for mild depression, $16.8 \%$ for moderate, $9.2 \%$ for severe and $2 \%$ for extreme depression $(31,32,33)$. Several explanations can be suggested for the discrepancy observed. First, the instruments used in the studies were different. The socio-demographic characteristic, prison status, and cultural differences between this study population and the listed studies may have contributed to the variation. The studies were conducted many years ago and prevalence of depression may have changed within the period. The harsher prison condition heeded in the locale of the prison for this study may also have contributed to the higher prevalence observed.

The youngest and oldest inmates in this study were 16 and 78 years respectively, with a mean age of 24.1. This finding is close to a study done in Jimma Town Prison, Southwest Ethiopia, where the median age of the respondents was 26 years, and to a study done in Northwest Amhara Regional State, Ethiopia, where the median age of the respondents was 27.75 (33). Participants in a prison study conducted in Iran were aged from 17 to 76 years with a mean age of 32.7 years. While the minimum and maximum ages of the respondents were comparable with this study, the mean age was not (30).

Out of 344 inmates in this study, $341(99.1 \%)$ were males and $3(0.9 \%)$ were females with a male to female ratio of 0.009 . This finding is comparable with other studies in various areas. In a study done in Port Harcourt Prison, of 400 respondents, $392(98 \%)$ were males and $8(2 \%)$ were females with male to female ration of 0.02 . From 649 respondents in a study done in Northwest Amhara Regional State, $583(89.8 \%)$ were males and 66 $(10.2 \%)$ were females with male to female ratio of 0.11 (51). It is also in line with a study done in Jimma Town Prison, where out of 332 respondents, $311(93.7 \%)$ were males and $21(6.3 \%)$ were females with male to female ratio of $0.006(33)$.

The study showed that inmates who were influenced by factors associated with future apprehension were more likely to show signs of depression when compared to their counterpart [AOR $=2.818 ; 95 \% \mathrm{CI}: 1.184,6.704$, $\mathrm{p}=0.019]$. In line with this finding, a study conducted in Northwest Amhara Regional State suggested that respondents who thought that they would face difficulties of running life as before after being free of imprisonment were $47 \%$ more likely to develop depression when compared to their counterpart (30). This could be because of the inmates' constant engagement in negative contemplations about their future's inconceivability and losing hope in the process which may in return result in depression. They are also the most stigmatized segments of the population in the society because of the offense they have afflicted and this may compliment their future apprehension. Aligned with this, inmates who were influenced by factors associated with the environment of the prison were more prone to the development of depression when compared to those who weren't [AOR $=0.043$; $95 \%$ CI: $0.003,0.564, p=0.017]$. The possible reason for this could be living with other prisoners who may be violent which may in return arouses serious feelings of insecurity and fear in the minds of the inmates. The prison environment is also unfitting and may lead to discomfort and disconcert; both advancing the genesis of development of depression.

The study also revealed that the odds of developing depression among inmates who had plans to commit suicide were more than 25 times more likely to develop depression compared to prisoners who didn't have plans to commit suicide $[\mathrm{AOR}=25.547 ; 95 \% \mathrm{CI}: 12.166,53.648, \mathrm{p}<0.01]$. This finding is comparable with the reports 
of World Health Organization and American Psychiatric Association which stated that mental health disorders (especially depression) were related to more than $90 \%$ of all cases of suicide (10). This finding is also comparable with a study conducted in Nepal (31).

\section{Limitations of the study}

Although the study addressed very important factors associated with depression, it is still not free of limitations. The study didn't collect information on the injury and trauma as they might be other factors associated with depression and the areas that are yet to be studied in this population include socio-economic and life style conditions of prisoners in prison like food, place of sleep, and recreational activity.

\section{Conclusion}

In conclusion, the prevalence of depression among inmates in Ambo Prison was found to be high, in which most of them met the criteria for severe depression contributing to suicidal ideation and actual attempts. Inmates who stayed in prison for more than a year, whose overall health status worsened compared to times before incarceration, who afflicted offenses unintentionally, who were influenced by factors associated with disconcerting sentiments, factors associated with future apprehensions, and factors associated with the environment of the prison, and inmates who had attempted suicide were more likely to have depression. Therefore, urgent attention should be issued to address the prevalence, severity, and associated factors of depression of the inmates through proper diagnosis and inmates should receive an equivalent mental health and well-being service to that available to the general population with access to services based on need.

\section{Recommendations}

1. Legislation should be introduced by the concerned bodies which allows for screening and referring of prisoners to general hospital psychiatric facilities.

2. Prisoner's mental disorder should be taken as one of public health problem and be prevented by creating conducive environment

3. Training on depression issues should be provided to all people involved in prisons including prison administrators, prison guards, and health workers in order to increase recognition and prevention of suicides.

4. Prisoners and their families should receive information and education on the nature of depression to promote mental health.

5. Prisons should find a way to maintain high observance, daily head counts and less access to any means of suicide.

6. Further studies investigating the negative consequence of depression among prisoners might be relevant.

\section{References}

1. Amayas Morse (2017), National Audit Office (NAO): mental health in prisons, 29 June, 2017.

2. Jordan BK, Schlenger WE, Fairbank JA, Caddell JM (1996). Prevalence of psychiatric disorders among incarcerated women II. Convicted felons entering prison. Arch Gen Psychiatry 1996; 53: 513-519.

3. Muakad JB, PrisaoAlbergue, Sao Paulo. Brazil: Atlas. $3^{\text {rd }}$ edition, 1998.

4. Moraes P, Dalgalarrondo P. women imprisoned in Sao Paulo. Mental health and religiosity. J Bras Psiq 2006; 55: $50-56$.

5. Drapalski AL,Youman K, Stuewig J, Tangney J (2009). Gender difference in jail inmates' symptoms of mental illness, treatment history and treatment seeking. CrimBehavMent Health 2009; 19: 193-206.

6. Fermandes R, Hirdes A. Convicts' perception of prison as deprivation of liberty. Rev Enf UER 2006; 14: 418424.

7. The prevalence of depression and determinants among adult patients admitted in governmental hospitals, Mekelle, Tigray, Ethiopia.Article, 2012.

8. Cecil R. Raymond, Randy W. Kamphaus. Diagnostic and Statistical Manual of Mental Health Disorders, fifth edition. American Psychiatric Association, 2013.

9. World Health Organization Fact Sheet. "Depression: let's talk" says WHO, as depression tops list of causes of ill health, 2017.

10. World Health Organization: Depression and other mental disorders. Global health estimates, 2017.

11. Morakinyo O. The nature and diagnosis of depressive disorders in Africans. In Morakinyo O. (ed): Handbook for students on Mental Health Posting, lle-lfe: The Department of Mental Health, ObafemiAwolowo University | ObafamiAwiolowo University. Teaching Hospital Complex, 2012.

12. Ohaeri JU, Jegeda RO. Depression and the general medical practitioner in Nigeria. Medicare 1991; 6: 7-11.

13. Ulzen TP., Hamilton H. The nature and characteristics of psychiatric comorbidity in incarcerated adolescents. Can J Psychiatry 1998; 43: 57-63. 
14. Joukamma M. Psychiatric morbidity among Finnish prisoners with special reference to socio-demographic factors: Results of the Health survey of Finnish prisoners (Wattu project). Forensic SciInt 1995; 73: 85-91.

15. Alize J. Ferari, Fiona J. Charlson, Rosana E. Norman, Scott B. Patten, Greg Freedman, Chrisopher J.L Murray, Theo Vos, and Harvey A. Whiteford. Burden of depressive disorders by country, sex, age, and year: Findings from the Global Burden of disease study in 2010. Published: November 5, 2013.

16. Lopez, A.D, Murray, C.C. "The global burden of disease, 1990-2020”. Nature medicine. (1998-1-01); 4(11): 1241-1243.

17. Ethiopian Journal of Health Sciences: Prevalence and risk factors of depression in Ethiopia, Jimma University: a review.

18. Abdulahi A., Damen H., Dereje K., Burden of disease analysis in Rural Ethiopia. Ethiopian Medical Journal. 2001; 39: 281 .

19. Her majesty's prison and probation service, NHS England and Public Health England: Mental Health in Prison. HC 42 Sessions 2017-2019, 29 June 2017.

20. Esker David (2010), Behavioral activation for depression delivered by mental health urses. A systematic review of the evidence and controlled clinical trial. Int. Jof Mental Health Nurs 3:3.

21. Parkes JH, Freshwater DS. The Journey from Despair to Hope. An exploration of the phenomenon of psychological distress in women residing in secure Mental Health Services. J PsychiatrMent Health Nurs, 2012; 19: 618-628.

22. Kuosmanen L. Attitudes towards depression treatment in primary care in Finland. $16^{\text {th }}$ International Network for Psychiatric Nursing Research (NPNR) Conference, Oxford, England, 2010.

23. Fatoye FO, Fatoye GK, Oyebanji AO, Ogunro AS. Psychological characteristics as correlates of emotional burden in incarcerated offenders in Nigeria. East Afr Med J 2006; 83: 545-552.

24. Douley E. Prison Suicide in England and Wales, 1972-87. Br J Psychiatry 1990; 156: 40-45.

25. Gebi H, Markos T, Desta H, and Hailu F. Assessment of prevalence and risk factors of depression among adults in Gilgel Gibe Field Research Center, South West Ethiopia. Journal of Depression and Anxiety, 2017, 6.1 .

26. Lindquist $\mathrm{CH}$, Lindquist $\mathrm{CA}$. Gender differences in distress: mental health consequences of environmental stress among jail inmates. Behar Sci Law 1997; 15: 503-523.

27. Heidi W. Depression as a leading contributor to Global Burden of Disease. Population Reference Bureau, 2006.

28. Chisholm D, Sanderson K, Ayuso-Mateos JL, Sexena S. Reducing the global burden of depression: population-level analysis of intervention cost-effectiveness I 14 world regions. Br J Psychiatry 2004184 : 393-403.

29. Bartol CR, Bartol AM. Psychology and Law: research and application, Pacific Grove, CA, $2^{\text {nd }}$ edition, 1994.

30. Sarhandi I. psychiatric morbidity among prison inmates at the central prison Karachi, Pakistan, The Health | Volume 5 | Issue 2 | 21.

31. Gambhir S, Deepak K. Yadav, Paras K. Pokharel. Depression among inmates in a regional prison of eastern Nepal: a cross-sectional study. BMC Psychiatry Article.

32. Teresa K. Beyan, Abel F. Dadi, Berihun A. Dachew, Niguse Y. Muluneh, Telake A. Bisetegn. Research article: more than eight in every nineteen inmates were living with depression at prisons of Northwest Amhara Regional State, Ethiopia, a cross-sectional study design.

33. Zakir Abdu, TeshomeKabeta, LammesaDube, WorkineshTessema, MubarekAbera. Prevalence and associated factors of depression among prisoners in Jimma town prison, Southwest Ethiopia. 